\title{
Affect Theory, Religion, and Sport
}

\section{Eric Bain-Selbo}

Department of History, Political Science, and Philosophy, Indiana University Kokomo, Kokomo, IN 47405, USA; ebainsel@iu.edu

Received: 26 June 2019; Accepted: 10 July 2019; Published: 31 July 2019

Abstract: Affect theory has made important contributions recently to the study of religion, particularly drawing our attention away from ideas and practices to the emotional or affectual experience of religion. However, there is a danger that affect theory may become yet another "protective strategy" (to use a term from philosopher of religion Wayne Proudfoot) in academic wars about the nature of religion. As a consequence, there is a danger that affect theory will become too restrictive in its scope, limiting our ability to use it effectively in investigating "religious" or "spiritual" affects in otherwise secular practices and institutions (such as sport). If we can avoid turning affect theory into a protective strategy, it can become a useful tool to provide insights into the "spirituality" of sport.

Keywords: affect theory; sport; religion; spirituality; phenomenology of religion

This essay is speculative in nature. Relatively speaking, affect theory is still new in terms of its application to the study of religion, and its full benefits may not come to fruition for some time. However, it holds great promise as a tool in our efforts to understand the emotional or affectual experience of religion as opposed to its mere doctrines and practices. In addition, it holds great promise as a tool for understanding the religious or spiritual dimensions of secular or seemingly non-religious cultural phenomena-in particular, in our case, sport. However, the utility of affect theory can only be realized fully if we avoid turning it into what may be called a "protective strategy".

In this essay, I will argue that affect theory can be an effective tool in the study of religion and popular culture (including sport), but only if we understand and use it in a particular way. After summarizing a common understanding of affect theory, I turn to philosopher of religion Wayne Proudfoot and his powerful critique of "protective strategies" in the study of religion. In the process, I will show how Proudfoot's critique can help us in maintaining a proper view of affect theory and its application to the study of religion. I conclude by noting how an appropriate view of affect theory is critical to the study of the religious or spiritual dimensions of sport.

\section{Affect Theory}

Affect theorists often describe their object of study in negative terms-what affects are not or what they are not connected to. For example, two primary characteristics of affects are, first, that they are pre-discursive or not directly related to or dependent upon language and, second and relatedly, that affects are not to be understood as necessarily inferior to reason.

Donovan O. Schaefer describes affects as "the flow of forces through bodies outside of, prior to, or underneath language". ${ }^{1}$ In other words, "affect or affects can be understood as the propulsive elements

\footnotetext{
1 (Schaefer 2015).
} 
of experience, thought, sensation, feeling, and action that are not necessarily captured or capturable by language or self-sovereign 'consciousness'". ${ }^{2}$ Take the example of joy. John Corrigan writes:

So, affect theorists see in the smile a sign of an affective fact, the affect of joy. That joy, displayed on the face, is not something that persons have to talk themselves into. It is a physically embodied emotion, but not one that requires the discourse of culture-however those are defined and displayed-in order to take place. ${ }^{3}$

The idea that emotions or affects must be dependent on language is part of what Schaefer calls the "linguistic fallacy". He explains:

The linguistic fallacy affirms that depth can't exist without language- that we can't want things without being told that we want them, without deciding that we want them, or without learning to want them. This is the presupposition of classical psychological behaviorism as much as textualism. But affect theory suggests that our animal intimacy with the world precedes constitution inside a linguistic frame-that there are "Proustian nooks" that pull us into the world without the application of language. The relationship between the affect and power moves bodies transversally through and across the grids of language, consciousness, or cognition. The compulsions of affect are better understood as addictions, as thick passions for bodies, objects, and relationships. ${ }^{4}$

Not only are affects independent of language, but they often are more powerful. "Affects are not passive receptors of inconsequential feeling that serve as window dressing on the linguistic architecture of power", Schaefer concludes, "power moves bodies through the pulsing of mobile, uneven affective systems. The linguistic $I$ is a figurehead monarch in this field of recalcitrant attachments." ${ }^{\prime 5}$

Because language and reason are so bound together, it is not surprising that affects are seen as being in a complicated, if not contentious, relationship to reason. "To study affects is to explore nonsovereign bodies, animal bodies", Schaefer argues, "bodies that are propelled skittering forward by a lattice of forces rather than directed by a rational homunculus" ${ }^{6}$ He adds:

Affects invert the metaphysical emphasis on the human's rational sovereignty over its body, retracing us as nests of animal becoming, finding pleasure in spinning out of control. Affective economies are directed by compulsions—-by autotelic forces that derail the abacus of rational self-interest. ${ }^{7}$

However, it is not the case that we now have a dichotomy with elements or aspects (affects and reason) that never interact and remain solely in their domains. In other words, there is not feeling and thinking separately. There are feelings to thinking and feelings to knowledge production, as well as the holding of knowledge. "Within the framework of affect theory, affect animates every aspect of embodied life, including the ostensibly affect-neutral domain of knowledge-production", Schaefer insists. "Affect theory prompts us to ask not just what we know, not just how we know, but how knowledge feels". ${ }^{8}$

By elevating the role of affects vis-à-vis reason and knowledge, affect theorists deconstruct a powerful and persistent view of the hierarchical structure of the human being. This hierarchy certainly dates back millennia and posits our rational nature as superior and controlling and our affectual or

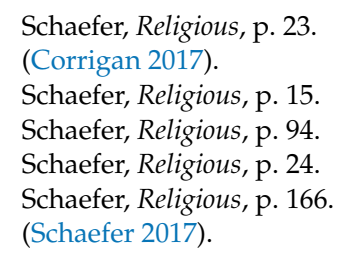


emotional nature as inferior and in need of control. "Separating reason and emotion denigrates the embodied nature of cognition, resorts to an ancient dualism of mind and body, and erects a hierarchy of thought, feeling, and body that skews the explanation of human behavior as properly rational", David Morgan observes. "The resulting dualism is strongly disposed to regard emotion as suspect for its inherent tendency to move one independent of reason". ${ }^{9}$

Liberated from language and rationality, affects can be seen as "ends in themselves". ${ }^{10}$ What Schaefer means by this is that affects cannot be reduced to other phenomena. For example, they are not merely the epiphenomena of language, culture, or rationality. In this sense, we might see an analogy between the way that affect theorists treat affects as sui generis and the way that Mircea Eliade, perhaps the 20th century's most prominent scholar of comparative religion, treats the sacred as sui generis. ${ }^{11}$ As we will see below, there are two related questions: Are affects sui generis? Or, are religious affects sui generis (though other affects may not be)? Answering affirmatively to the second question in particular might provide the theoretical basis for a "protective strategy" for religious phenomena that isolates or protects certain claims about religious affects from rational inquiry.

The independence of affects from language and reason is critical when studying religion. Affect theory draws us to these powerful elements in human beings-elements that are not simply activated by or determined by language and rationality but exist independently and prior to or outside of all language and reason. Schaefer insists that "affects are not simply to be understood as passive channels activated by the play of language hovering over them. Rather, affects surge through bodies, producing semistable structures that become the tough, raw materials of religion". 12

Part of the problem with the past study of religion has been its focus on language-the "linguistic fallacy". "The linguistic fallacy misunderstands religion as merely a byproduct of language", Schaefer writes, "and misses the economies of affect-economies of pleasure, economies of rage and wonder, economies of sensation, of shame and dignity, of joy and sorrow, of community and hatred-that are the animal substance of religion and other forms of power" ${ }^{13}$ Looking behind or before language leads scholars then to a new and very different approach to the study of human beings and culture in general and religion in particular. For Schaefer, such an approach even closes the gap between human beings and other animals. He insists:

[A]t the emotional and preemotional levels, affects are the flexible architecture of our animal lifeways, the experiential shapes that herd together and carry religion on their backs. Affect theory makes available a set of approaches to religion that work through animality by probing the thick forms moving outside of the narrow lighted circle of language. ${ }^{14}$

Affects are like the foundation of a house upon which reason, desires, and human action build cultural phenomena-for example, religion.

For Schaefer, affects are both the prelinguistic foundation of religion and a consequence of religious activity. "Religion as a composite of compulsions is made possible by existing, intransigent bodily technologies", he writes, "but it also motivates, activates, and drives those technologies". ${ }^{15}$ Rather

\footnotetext{
(Morgan 2017).

Schaefer, "Beautiful", p. 79.

11 Schaefer also is interested in how affects are related to power. For him, "Affects fuse together to shape the planes of interface between bodies and power" (Schaefer, "Beautiful", p. 77). He also states, "Affect theory in all its forms is designed to profile the operations of power outside of language and the autonomous, reasoning human subject" (Schaefer, Religious, p. 23). Schaefer's work in this direction is interesting and worth engaging but not critical for our purposes.

12 Schaefer, Religious, p. 39.

3 Schaefer, Religious, pp. 9-10.

4 Schaefer, Religious, p. 24.

15 Schaefer, Religious, p. 134. He adds: "Religion is an extraordinarily powerful distribution network through the global nervous system of affect" (Schaefer, Religious, p. 175).
} 
than arguing for a simplistic cause-and-effect position (religion causes affects or affects cause religion), Schaefer is defending a more circular understanding of the relationship. ${ }^{16}$

In situating affect theory in the broader history of the study of religion, it is reasonable to wonder if it is a new version of the phenomenological approaches of figures such as Rudolf Otto or Mircea Eliade. In one sense, affect theory can embrace that phenomenological history. Similar to Otto's "idea of the holy" or Eliade's experience of the sacred, affects have a sui generis character. On the other hand, someone such as Schaefer is hesitant to embrace the "ahistorical metaphysical essentialism of Eliade"17-insisting on the cultural context and historical grounding of affects. The question is the following: Are there religious affects or simply affects that tend to occur as a consequence of religious practices or in religious settings? If the latter, then we certainly have something very different than the phenomenological approach of Otto or Eliade. However, if it is the former, affect theory would seem to come particularly close to the kind of sui generis arguments of scholars such as Otto and Eliade. Before answering the question, however, it will be helpful to look at the work of Wayne Proudfoot, a philosopher of religion who offers a powerful critique of the phenomenological approach —one that might serve as a warning to affect theorists.

\section{Wayne Proudfoot on Religious Experience and Protective Strategies}

Affect theory is far from the first attempt to draw our attention away from language and reason and focus on emotion or feeling instead. In the 19th century, theologians and scholars of religion started to identify feeling or emotion as that which was most characteristic of religion. Wayne Proudfoot argues that this primarily occurred for two reasons. First, it was deemed that feelings or emotions are more grounded in the lived experience of adherents than is doctrine. Feelings or emotions are more powerful than dogma. Second, the move to feelings or emotions helped to avoid a rationalist critique of religion. At least since the Enlightenment, religious doctrine had been subject to powerful philosophical criticism. Indeed, in the 19th century, through the 20th century, and continuing into the 21st century, many intellectuals predicted and still predict the demise of religion as individuals and whole societies become more rational. However, reason often reaches a certain limitation (so it is thought) when confronted with feelings or emotions. At the very least, feelings or emotions do not seem subject to the same level of rational critique as does doctrine. ${ }^{18}$ Our feelings or emotions are natural or intrinsic elements of the human condition in the same way that some theorists speak of affects today.

Christian theologians such as Friedrich Schleiermacher and Rudolf Otto, whose interests included the more general study of religion as well, were instrumental in moving the study of religion in this theoretical direction. The former emphasizes the role of non-cognitive feelings or intuitions as foundational to religion, while the latter describes feelings of awe, energy, and mystery (among others) that are constitutive of religious experience. William James, the early 20th-century philosopher and psychologist, also emphasizes the subjective experience of religious phenomena as central to the study of religion. His Varieties of Religious Experience is a seminal work in the typology of religious experience. He describes religion not in terms of doctrines or institutions but as "the feelings, acts, and experiences of individual men in their solitude, so far as they apprehend themselves to stand in relation to whatever they may consider the divine" ${ }^{19}$ Eliade, of course, also focuses on subjective experience. In his phenomenology of religion, Eliade argues for the qualitatively greater experience associated with the sacred as opposed to what is associated with the profane.

16 Religion also is an area where Schaefer analyzes power. He notes, "Religion, like other forms of power, moves bodies by creating affective ligatures between bodies and their worlds" (Schaefer, Religious, p. 179). In other words, religions "like other formations of power, are reservoirs of compulsory links to the world" (Schaefer, Religious, p. 207). In the end, he concludes: "Affects wordlessly crawl through our bodies on the way to the world, producing systems of power as they do-some of which get called religious" (Schaefer, Religious, p. 218).

17 Schaefer, Religious, p. 8; also see Schaefer, Religious, pp. 54, 59.

18 (Proudfoot 1985).

19 (James 1961). 
Wayne Proudfoot offers a compelling critique of this historical and theoretical development in the study of religion. He finds that many of the approaches to understanding religious experience simply protect that experience against rational investigation and criticism. One cannot rationally dismiss, for example, that which precedes or is beyond reason (a popular argumentative strategy, of course, for those who defend claims about the existence of God or gods). However, these "protective strategies" fail philosophically. Take, for example, Proudfoot's critique of Schleiermacher-one that can be (and is) extended to other theorists as well.

Schleiermacher describes religious experience as an immediate apprehension of the divine or religious object or being. By making the religious experience immediate, Schleiermacher preserves it against the argument that it is the "idea" or "thought" of the divine that causes the experience and, extending this, that the divine is merely an "idea" or "thought" and thus has no external reality (or, at least, following Kant, that we cannot know that reality). Religious consciousness, according to Proudfoot's reading of Schleiermacher, "is both intentional, in that it is directed toward the infinite as its object, and immediate. It is not dependent on concepts or beliefs, yet it can be specified only by reference to the concept of the whole or the infinite". ${ }^{20}$ Taken together, however, these claims are contradictory. "If the feeling is intentional", Proudfoot writes, "it cannot be specified apart from reference to its object and thus it cannot be independent of thought". ${ }^{21}$ In other words, Schleiermacher "defends the incoherent thesis that the religious consciousness is both independent of thought and can only be identified by reference to concepts and beliefs". ${ }^{22}$ He cannot have it both ways. Either religious experience is truly immediate (i.e., not mediated by thought), in which case it becomes hard to identify it vis-à-vis an intentional object (thus, why even call it "religious"), or it is mediated by thought, in which case it is not immediate and thus open to rational inquiry and criticism.

There are at least two key points that come out of Proudfoot's critique of Schleiermacher-again, points that can be extended to subsequent theorists who attempt (either explicitly or implicitly) to protect religious experience from critical inquiry. First, Proudfoot makes the point that religious language is both expressive and formative of experience. Religious language may describe an experience but the words and ideas that we associate with religious language also cause or at least shape the experience itself. Thus, Proudfoot argues that religious language "is not only the expressive, receptive medium Schleiermacher takes it to be. It also plays a very active and formative role in religious experience". ${ }^{23}$ The second (related) point is that it is illegitimate to separate religious feeling or emotion (in short, religious experience) from thought. Proudfoot admits that Schleiermacher "is correct to view primary religious language as the expression of a deeply entrenched moment of consciousness", but he is "incorrect to portray that moment as independent of thought and belief. Schleiermacher has mistaken a felt sense of immediacy for a guarantee that piety is not formed or shaped by thought or inference" ${ }^{24}$ Do affect theorists make a similar mistake?

The question of the cognitive status of feelings or emotions is critical and deserves more of our attention here. Take the example of anger. Anger is not an immediate emotional experience, unmediated by thought. How do we know when someone is angry? It certainly is not because we empathically feel what they are feeling. We ascribe anger to them based on the public evidence, based on how they are reacting. This ascription will include our interpretation of their actions relative to our understanding of the entire context in which they are acting. Frank seems agitated, and I interpret that as anger, because I know that he has just been told by his boss that he will not be receiving a raise this year. In short, my ascription of anger to someone is a consequence of my reflection about all sorts of

\footnotetext{
Proudfoot, p. 11.

Proudfoot, p. 11.

Proudfoot, p. 18.

Proudfoot, p. 40.

Proudfoot, p. 36.
} 
pieces of evidence provided to me. What is even more interesting is that our self-ascription of anger is very similar. As Proudfoot argues:

I don't appeal to private inner states in ascribing emotions to myself any more than I do in ascribing them to others. I often come to know what I am feeling by interpreting physiological changes or my behavior in exactly the same way in which another might interpret them if the data were available to him..$^{25}$

Coming out of a meeting with my boss, I may notice that my heart is racing, and my teeth are clenched. These physiological changes alone are not enough for me to determine that I am angry. Certainly, they can contribute to such a determination, but I will come to ascribe anger to myself by interpreting the situation, realizing that my boss is a jerk and that I have been treated poorly or unfairly by her. Indeed, I may not even realize that I am angry based just on increased heart rate and clenched teeth. I may not even notice these physiological changes. To that extent, the physiological changes alone do not constitute anger. Only when interpreted and understood within a context of perceived sleight, injury, etc. can we connect these physiological changes to the feeling or emotion of anger. The word "anger" is not merely a description of our experience, but is an interpretation of it. Proudfoot concludes that emotion words "are employed, not as simple descriptions of bodily changes, behavior, or dispositions to behave, but as interpretations and explanations of those phenomena". ${ }^{26}$ Even more, the interpretation is constitutive of the very experience.

Proudfoot turns to the psychological research of Stanley Schachter to further his argument. Schachter's experiments confirm that physiological changes alone are not clear indicators of particular emotions or feelings. In other words, the same physiological changes may be interpreted in different ways depending on the person who is experiencing them and the context in which they occur. However, what is the relevance of Schachter's work for Proudfoot's interest in religious experience and for our own concerns here? "Given the results of Schachter's experiments," Proudfoot concludes, "it seems quite plausible that at least some religious experiences are due to physiological changes for which the subject adopts a religious explanation". ${ }^{27}$ Thus, if understood in the same way that we should understand other emotions or feelings, the physiological changes (the felt experience) of the religious experience are in fact religious to the extent that they are interpreted religiously-they are not intrinsically religious.

This understanding of what constitutes an experience is critical to Proudfoot's distinction between descriptive and explanatory reduction in the study of religious experience. Descriptive reduction is "the failure to identify an emotion, practice, or experience under the description by which the subject identifies it. This is indeed unacceptable". ${ }^{28}$ Proudfoot uses the example of a hiker seeing a bear in the woods, the sighting leading to an experience of fear in the hiker. As it turns out, it really was not a bear but a tree stump instead. It would be a case of descriptive reduction to claim that the hiker was in fear of a tree stump. The tree stump indeed was the object he saw, but he thought it was a bear. To say that he was afraid of a tree stump would be to fail to make sense of the story. Still, it would not be wrong to say that the cause of his fear was a tree stump that looked to him (perhaps at a distance, through some fog or mist, etc.) like a bear. We also must take account of the hiker's understanding of the danger of bears or even his past experience with bears (maybe he was mauled as a child?). Including this information in our account of the incident would be leading us toward explanatory reduction, "offering an explanation of an experience in terms that are not those of the subject and that might not meet with his approval. This is perfectly justifiable and is, in fact, normal procedure". ${ }^{29}$ It might be

\footnotetext{
25 Proudfoot, pp. 92-93.

26 Proudfoot, p. 93.

27 Proudfoot, p. 102.

28 Proudfoot, p. 196.

29 Proudfoot, p. 197.
} 
that the hiker refuses to believe that there was no bear-that what he really saw was a tree stump. I certainly am not obligated simply to accept his account of the experience, especially if I have strong evidence supporting the claim that what he saw really was a tree stump. In other words, I have to take him seriously when he says that he saw a bear and that this is what made him afraid, but I need not accept that as the final explanation of the event. I clearly have solid evidence of the tree stump, and I might even be able to make the case that the hiker suffers from paranoia vis-à-vis bears (thus leading to the mistaken identification of the tree stump as a bear). Proudfoot concludes:

Where it is the subject's experience which is the object of study, that experience must be identified under a description that can plausibly be attributed to him.... The explanation the analyst offers of that same experience is another matter altogether. It need not be couched in terms familiar or acceptable to the subject. It must be an explanation of the experience as identified under the subject's description, but the subject's approval of the explanation is not required. ${ }^{30}$

All of this can be applied to religious experience in the following way. If a religious adherent claims to have had a religious experience of God's love-a uniquely religious love unlike any other experience of love- then any investigation of this experience must begin with the adherent's description. However, a full explanation of the experience may entail an account of the full context in which the experience occurred in order to more accurately identify the factors or causes that gave rise to the experience. For example, perhaps it was an emotionally taxing period in the adherent's life. Maybe she was part of a prayer group that emphasized the experience of God's love during its communal activity. Maybe she was on medication that fostered such loving emotions. In short, many factors may have led to her experience of God's love, and we need not accept the sui generis character of that experience any more than we need accept the reality of God. Naturally, she might reject these latter explanations. However, while we must begin with her description, we need not end up there. As Proudfoot argues, "To require that any explanation of a religious experience be one that would be endorsed by the subject is to block inquiry into the character of that experience". ${ }^{31}$ In other words, if all I can do is to accept her description of the experience, then there is no room for any other explanation nor even for an investigation of her experience in the first place.

Proudfoot concludes that the "distinguishing mark of a religious experience is not the subject matter but the kind of explanation the subject believes is appropriate". ${ }^{32}$ Another way of putting this is that it is not the content (increased heart rate, feelings of elation, forms of ecstasy, etc.) of the experience that defines it, but the explanation we give to that content. For example, in the case of experiences surrounding the participation (either as an athlete or spectator) in sporting events, it very well could be that the participants have similar physiological and psychological experiences that religious practitioners have, but the former are not having "religious" or "spiritual" experiences, because they simply do not label them that way as do the latter. If, for example, the participants in the sporting event had a different understanding of what religion is or what a spiritual experience is, perhaps they more likely would apply these terms to describe their experiences and, thus, those experiences legitimately could be considered religious or spiritual.

The approach Proudfoot represents certainly opens up popular culture generally and the experience of the sporting event more specifically to a deeper and more thorough investigation. There are other theorists whose work supports or is supported by such an approach. Mihaly Csikszentmihalyi champions the psychological concept of "flow". Flow involves the immersion of the individual psyche in an activity that is productive, creative, and personally valuable. Flow is "the state in which people are so involved in an activity that nothing else seems to matter; the experience itself is so enjoyable

\footnotetext{
30 Proudfoot, p. 195.

31 Proudfoot, p. 200.

32 Proudfoot, p. 231.
} 
that people will do it even at great cost, for the sheer sake of doing it". ${ }^{33}$ Flow experiences can occur in all sorts of activities, ranging from painting a picture to dancing to making a cabinet. They can occur in religious settings. They can also occur in sports. "Play, art, pageantry, ritual, and sports are some examples [of flow]", Csikszentmihalyi writes. "Because of the way they are constructed, they help participants and spectators achieve an ordered state of mind that is highly enjoyable". ${ }^{44}$ He adds that in the sporting event "players and spectators cease to act in terms of common sense, and concentrate instead on the peculiar reality of the game". ${ }^{35}$ Thus, the flow experience is common or universal whether it occurs in the art studio, the church, or the stadium - it is just that the contexts will shape how we label the flow experience.

If the content of the experience is similar (ecstasy, "flow", etc.) but we simply label it differently, then it should not surprise us when people decide that it is appropriate and perhaps necessary to use religious language to more accurately describe the experience of the sporting event. They have come to believe that the content of the experience is similar to if not identical with those experiences described by religious practitioners (for example, mystics). Howard Slusher insists: "Something of faith, something of peace, a touch of power, a feeling of right, a sense of the precarious-all of these and more is what real spirit of sport is". ${ }^{36}$ He acknowledges the mystical dimension of sport and religion, concluding that both "open man towards the acceptance and actualization of being". ${ }^{37}$

It is important to remember, however, that Proudfoot makes a convincing case that our labels of experiences do not merely describe them but help to constitute them. There still might be something different about the religious experience-because it in part is constituted by religious concepts and ideas-that separates it from the often equally powerful experiences at the sporting event. However, here we are pushed to our reflective limits and the recognition that we are now probing psychological and existential areas where we cannot have anything close to definitive answers. Is there a difference between the ecstasy in the pews and the ecstasy in the bleachers? Given the complexities and subtleties of psychological states, we probably can never know. However, we should not begin our investigations with theories that are "protective strategies", that separate out some experiences as sui generis, that close off avenues of inquiry about the similarities or even identical natures of human experiences.

\section{Critique of Affect Theory}

So, what of affect theory? Does Proudfoot's critique of the phenomenological approach pose a threat to affect theory as an approach to the study of religion? As with a lot of questions, it depends. It depends most significantly on whether we think there are fundamental affects as part of the human condition or that there are specific affects that are irreducibly religious.

If the claim by affect theorists is that there are affects that are exclusively religious affects, then we return to something like the sui generis argument of Eliade and others-the kind of argument that Proudfoot identifies as a "protective strategy". On the other hand, if we are talking about a set of general affects, some of which encourage and/or are activated by religious thought and actions, then we recognize the possibility that that subset of affects may also encourage and/or be activated by thought and actions that may be stereotypically secular in character.

Schaefer is not always clear on this issue. Generally, he writes about affects as universals that can be connected to a wide variety of practices, institutions, and structures. At other times, however, he suggests the existence of specifically religious affects. Indeed, even the frequent reference to religious affects (including in the title of his book) suggests that there are actual affects that are religious in nature. Beyond just the use of the adjective "religious", however, there are passages that seem to

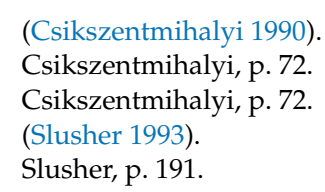


claim the existence of specific religious affects. For example, Schaefer states that affects "surge through bodies and compose themselves in religious forms". ${ }^{38}$ What are these "religious forms"? The phrase leads one to believe that affects change somehow into forms that are specifically religious. But how? Is simple joy different than religious joy? In another passage, Schaefer goes further, making it sound like there are permanent or eternal religious affects. In Religious Affects, he writes of "the multitude of subterranean ways that religion flows through our bodies". ${ }^{39}$ Is religion a "thing" that flows through bodies? We would hardly think so. Does Schaefer mean then that religious affects flow through bodies? In short, both passages suggest a return to the sort of sui generis arguments of the older phenomenological approach of Eliade and others.

Schaefer, in fact, tries to separate himself from this phenomenological approach. He imagines a line that goes roughly from Eliade and Otto to J.Z. Smith to affect theory. He considers Smith to be an important advance beyond the phenomenological tradition represented by Eliade and Otto and sees affect theory as an important advance beyond Smith.

What would Proudfoot say about the affect theory we find in Schaefer? Clearly, the claim that there are pre-linguistic affects that are "religious" (whatever that means) leads us right into the same problems that Proudfoot critiques in the phenomenological tradition. If they are pre-linguistic, then why call them "religious". In this sense, religious affects are akin to Eliade's experience of the sacred or Otto's mysterium tremendum. However, if affects are viewed as merely emotional experiences or states that can be elicited or activated in a number of different settings-some stereotypically religious and others seemingly secular-then we open up a much richer and defensible approach to the study of culture and cultural institutions and the human experience of them. In this regard, I agree with Abby Kluchin who warns, "Affect theory cannot afford to be so enchanted with itself-with its own bewitching linguistic formulations to capture the nonlinguistic — that it unwittingly re-enchants our thoroughly disenchanted world". 40

In his essay on religion, sport, and nationalism, David Morgan attempts to "thread the needle" on the problems raised above. "My contention will not be that sport or national piety is the new religion of modern society," he writes, "but rather that there is no need for the social or cultural analyst to erect a strong distinction among the three. They are not fully discrete any more than they are merely interchangeable" ${ }^{41}$ In other words, the affects associated with these three areas of cultural life are neither unique and irreducible nor exactly the same and interchangeable. There may not be a discrete set of religious affects wholly different from all other affects, but we still can talk about affects that either arise in a religious context or have a religious "flavor" to them.

Morgan relies upon the notion of "sacralization". "Sacralization is a procedure at work in any number of cultural activities, including but not limited to religion", he notes. "Thus, when fans say soccer is my religion, they may be understood to say something like soccer is how my people and I feel our common identity. They might say the very same of their nation and their religion". ${ }^{2}$ Morgan then rejects the notion that any of these categories needs to be "reduced" to the other-that sport is really religion or that religion is really nationalism or even that nationalism is really sport. He insists that "sacralization is not synonymous with religion nor is it essentially religious, but is rather the pervasive social mechanism for making something, someone, or someplace special. It happens in sports, art, politics, commerce, the family, and religions". ${ }^{43}$ In a sense, the point is that the noun (sport, art, "the sacred", etc.) is less important than the verb (sacralize)—-than the process by which something is made special. Morgan concludes that rather than reducing other cultural phenomena to

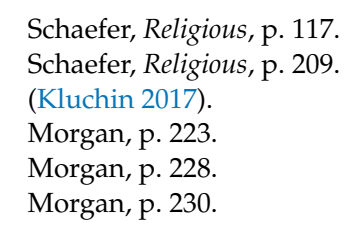


the phenomenon of religion or vice versa, "we get further by describing such modern experiences as sport, nationalism, and religion as ritual practices that generate powerful cultures of thought and feeling that enable moderns to imagine the bonds of affection that tell them who their group is and what matters to them". ${ }^{4}$

Morgan cites Ann Taves as a kindred spirit in this regard, and certainly her work makes a substantial contribution. She argues against the sui generis approach typical of phenomenologists such as Eliade - the idea that sacredness or holiness is some irreducible reality in the world. She argues that the "basic problem with the sui generis model is that it obscures something that scholars of religion should be studying: that is, the process whereby people constitute things as religious or not". ${ }^{45}$ In order to get away from problematic terms such as sacred and holy, Taves instead writes of "specialness". Things, people, places, actions, or times that are special can vary greatly. Many of these are stereotypically religious (e.g., a temple, a priest, a ritual, etc.), but what is special can also appear in contexts that are secular. In other words, the process of making something special is the big umbrella under which religion is but one institution-along with music, sport, nationalism, and much more. Special things, for Taves, are the "building blocks" of religion but also of many other cultural phenomena. ${ }^{46}$

Both Taves and Morgan, then, suggest a world of experiences or affects that are more universal in character and fluid between cultural phenomena. They represent a very different position than those who might posit the existence of uniquely religious experiences or affects.

\section{Conclusions}

It might help for us to imagine a spectrum of positions to take on the status of religious affects. At one extreme is the claim that there are affects that are religious-not reducible to other affects, unique, sui generis, etc. We might imagine Eliade and Otto occupying this position (if they were alive to join in the discussion), and Schaefer sometimes seems to drift in this direction (though, as stated, his position is not always clear). Thus, one might argue that there is a distinct religious experience of transcendence, of feeling part of something larger than oneself, and that this experience is unlike any similar sorts of experiences in different contexts.

At the other extreme is the claim that "affects are affects" - that affects are basic building blocks (to borrow Taves' term) of the human condition that can be found in religious contexts but in many other contexts as well. In this sense, religious affects are not unique affects. Rather, the word "religious" simply designates where the affects arise or are manifested or how they are interpreted rather than any irreducible or sui generis character that they have. Thus, one would argue that the experience of transcendence, of feeling part of something larger than oneself, is an experience that can happen in a religious context, but it may also happen at a political rally or in a sports stadium. The affect is the same, though the context might change. This position is supported by the work of Proudfoot, and Taves certainly can be read to lean in this direction.

Between these two extremes, of course, are myriad other positions-Morgan being but one example. However, it is hard to occupy a middle position on this issue, because the two extremes require an either/or choice. Either religious affects are sui generis, or they are not. Proudfoot opens the door to such middle positions by noting how language and/or context might shape experience rather than serve as mere interpretation. However, as I noted earlier, we are then "in over our heads" in terms of really figuring out and disentangling cause and effect here. We are beyond being able to come up with definitive answers. That said, and while I cannot fully defend the claim here (the claim may even

44 Morgan, p. 238.

45 (Taves 2009). It should be noted that Taves recognizes a fair amount of agreement between her position and Proudfoot's work (Taves 2009, p. 93).

46 Taves, p. 162. 
be indefensible or at least unproveable), I believe Morgan's position ends up being a theoretically untenable compromise.

In the end, I support Proudfoot's side of the spectrum. There certainly is a danger that affect theory turns us back to the problematic kind of protective strategy that Proudfoot powerfully identifies in the phenomenological tradition. I argue that the study of the full range of human affects in popular culture is only possible by avoiding that protective strategy and that the study of the full range of human affects in popular culture also helps us to avoid that protective strategy. Seeing the experiences of joy, "flow", and transcendence in a sporting event "disenchants" those experiences-frees them from the limitations of specifically religious contexts. If there is such a thing as religious joy, for example, that can mean one of two things. First, that there is an intrinsically religious character in a particular kind of joy that makes it different from any other joy-like affect. Here, we are in the neighborhood of Eliade and other classical phenomenologists. In that neighborhood, our questioning or inquiry into that joy is limited, for we first must accept the intrinsically religious character and that character, at least, cannot be questioned. Second, one might say that religious joy is the joy that occurs in a religious context. However, then the very phrasing "religious joy" is misleading, for what we really mean is that one might experience joy as part of a religious ritual or being in a religious building, but one also could experience that same joy in other contexts. Thus, instead of calling it religious joy, we simply should talk about joy as it may occur in a religious context. Now, we are in the neighborhood of Proudfoot-the neighborhood that I prefer. In this neighborhood, we can query more fully the nature of this joy-how it arises and how its appearance in a variety of contexts (religious or secular, in the temple or the stadium) can lead to powerful insights about it.

As a key element of popular culture, the study of sport by religious studies scholars is most fruitful when we avoid protective strategies (either ones we inherit or new ones of our own creation) and that same study implicitly makes the case against those protective strategies. Affect theory can be a powerful tool for religious studies scholars studying popular culture more generally and sports more specifically, but only if it avoids becoming a new protective strategy.

Funding: This research received no external funding.

Conflicts of Interest: The author declares no conflict of interest.

\section{References}

Corrigan, John. 2017. Introduction: How Do We Study Religion and Emotion? In Feeling Religion. Edited by John Corrigan. Durham: Duke University Press, p. 9.

Csikszentmihalyi, Mihaly. 1990. Flow: The Psychology of Optimal Experience. New York: HarperCollins, p. 4.

James, William. 1961. The Varieties of Religious Experience. New York: Collier Books, p. 42.

Kluchin, Abby. 2017. At the Limits of Feeling: Religion, Psychoanalysis, and the Affective Subject. In Feeling Religion. Edited by John Corrigan. Durham: Duke University Press, p. 257.

Morgan, David. 2017. Emotion and Imagination in the Ritual Entanglement of Religion, Sport, and Nationalism. In Feeling Religion. Edited by John Corrigan. Durham: Duke University Press, p. 225.

Proudfoot, Wayne. 1985. Religious Experience. Berkeley: University of California Press, pp. 75-78.

Schaefer, Donovan O. 2015. Religious Affect: Animality, Evolution, and Power. Durham: Duke University Press, p. 4. Schaefer, Donovan O. 2017. Beautiful Facts: Science, Secularism, and Affect. In Feeling Religion. Edited by John Corrigan. Durham: Duke University Press, p. 70.

Slusher, Howard. 1993. Sport and the Religious. In Religion and Sport: The Meeting of Sacred and Profane. Edited by Charles S. Prebish. Westport: Greenwood Press, p. 191.

Taves, Ann. 2009. Religious Experience Reconsidered: A Building-Block Approach to the Study of Religion and Other Special Things. Princeton: Princeton University Press, p. 21. 